\title{
КОНТРОЛЬ: ТВОРЧЕСКО-ПЕДАГОГИЧЕСКАЯ ФУНКЦИЯ УПРАВЛЕНИЯ УЧЕБНЫМ ПРОЦЕССОМ
}

Черепанова Ксения Александровна студент

Научный руководитель: Мухаева Замиря Ахнабовна к.ф.н., доцент Лысьвенский филиал ФГАОУ ВО «Пермский национальный исследовательский политехнический университет»

Аннотация: в статье рассмотрена актуальная тема контроля в учебном процессе, проиллюстрированы цель и задачи, а также виды. Для снятия эмоционально-тревожного состояния обучающихся при проведении контрольно-измерительных действий (тесты, практические, лабораторные работы и другое) предложено перейти на активные методы обучения, которые непосредственно связаны с преподавательской деятельностью.

Ключевые слова: контроль, педагогические требования, виды контроля, АМО, преподаватель.

\section{CONTROL: CREATIVE AND PEDAGOGICAL FUNCTION OF EDUCATIONAL PROCESS MANAGEMENT}

\author{
Cherepanova Ksenia Aleksandrovna \\ Scientific adviser: Mukhayeva Zamirya Akhnabovna
}

\begin{abstract}
: the article discusses the topic of control in the educational process, illustrates the purpose and objectives, as well as types. In order to relieve the emotional and anxious state of students during control and measurement actions (tests, practical, laboratory work, etc.), it is proposed to switch to active teaching methods that are directly related to teaching.

Key words: control, pedagogical requirements, types of control, AMO, teacher.

Контроль, проверка результатов обучения трактуется дидактикой как педагогическая диагностика. Также контроль как функция управления в педагогике является процедурой проверки результатов обучения, т.е. проверка знаний, умений и навыков обучающихся. Контроль - это неотъемлемая часть
\end{abstract}


проверки усвоения темы, по средствам проверки домашних заданий, различных контрольных работ, диктантов и многого другого [3].

Цель контроля в педагогике состоит в том, что преподаватель оценивает уровень знаний обучающихся, чтобы в дальнейшем скорректировать образовательное пространство и у обучающихся не было пробелов в знаниях при освоении программы по дисциплине.

Усвоение пройденного материала и его повторение позволят преподавателю организовать эффективное изучение нового материала. Все темы в дисциплине связаны друг с другом, буквально красной нитью перекликаются, в связи с чем, необходимо проводить контроль для того, чтобы не «западали» уже изученные материалы и осуществлялась проверка усвоения нового [1].

Контроль является сугубо творческой составляющей преподавателя, именно от него зависит эмоциональная составляющая в образовательном процессе. Что это значит? А то, что нельзя использовать контроль как средство наказания всей аудитории, в системе СПО и ВО, которая по какой-то причине не включилась в учебный процесс. Тотальный контроль на каждом занятии может вызвать у обучающихся неприязнь к дисциплине, а также длительную антипатию и к самому преподавателю. Уровень тревожности на таких занятиях превышен, каждый по разному переживает: кто-то нервно повторяет, кому-то уже всё равно (одной двойкой больше, одной меньше), кто-то заедает предстоящий стресс в столовой, другие активно обсуждают темы связанные с учёбой и так далее.

Контроль должен быть в меру, согласно учебному плану, не забывая, что образование есть среда, где механизм «человек-человек» является главной ценностью.

Задачи контроля:

- определить степень готовности к изучению новой информации обучающимися;

- выявить затруднения и ошибки в теме;

- определить методы и средства закрепления предыдущей темы;

- скорректировать подачу новой информации обучающимся;

- проконтролировать закрепление предыдущей и новой темы [3].

В учебном процессе контроль выполняет функции: оценочная, стимулирующая, воспитывающая, образовательная, развивающая корректирующая [2]. 
Теорией и практикой обучения установлены следующие педагогические требования к организации контроля за учебной деятельностью обучающихся (по Н.А. Сорокину), рис. 1 [2].

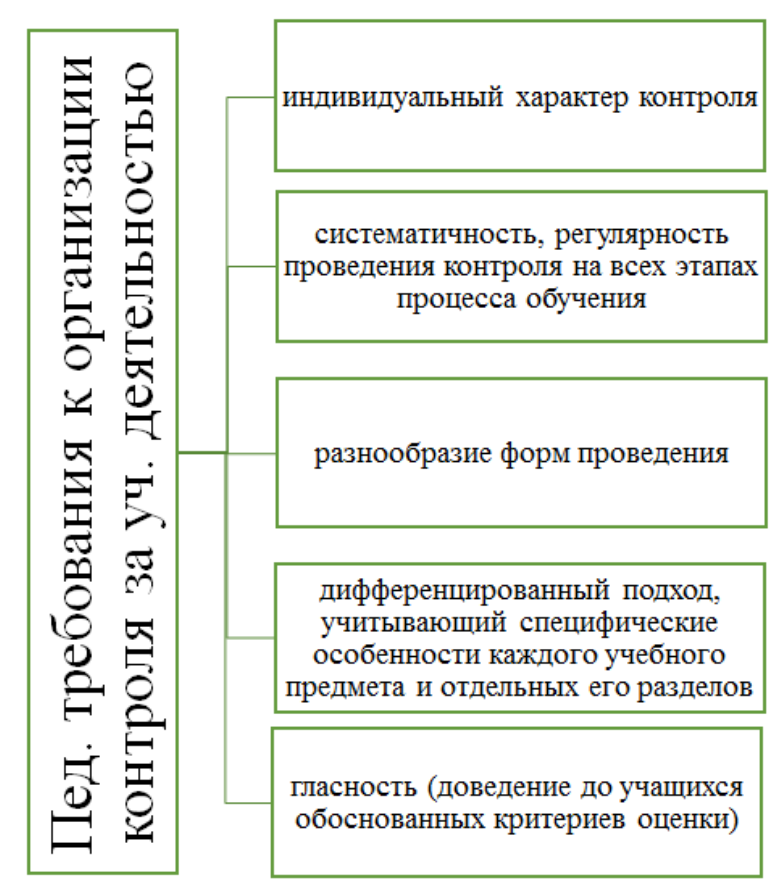

\section{Рис. 1. Педагогические требования к организации контроля за учебной деятельностью обучающихся}

Виды контроля в педагогике, а так же уточнения по каждому виду, представлены на рис. 2 [2].

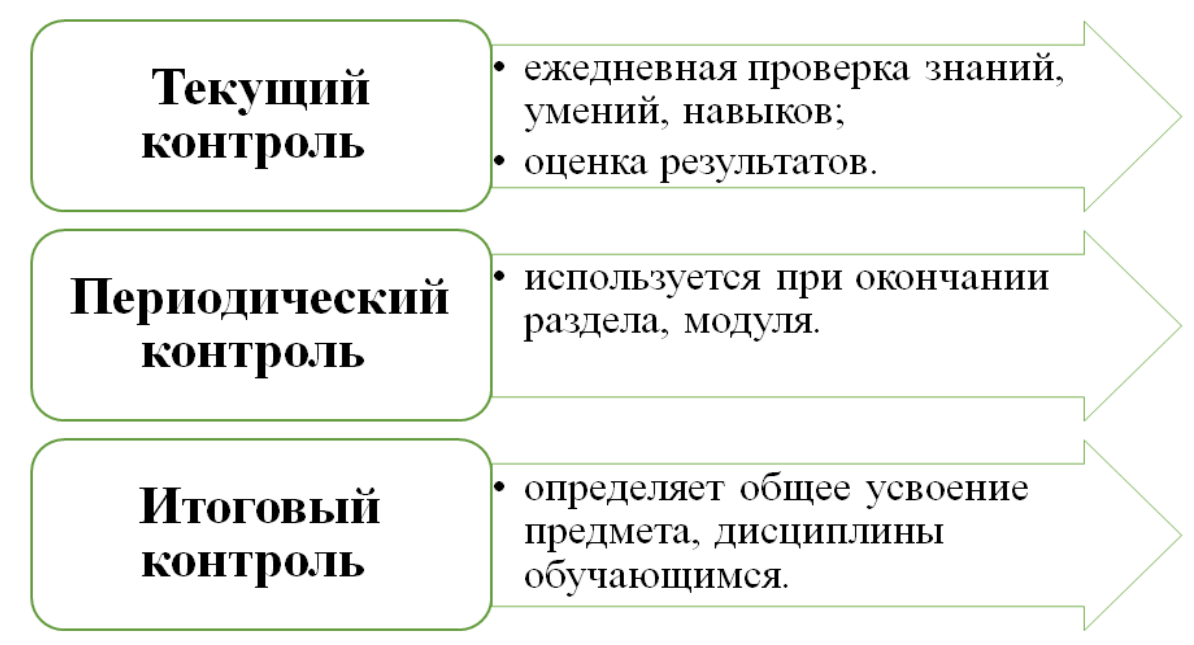

Рис. 2. Виды контроля в педагогике и уточнения 
В педагогике выделяют не только виды, но и методы контроля, рис. 3.

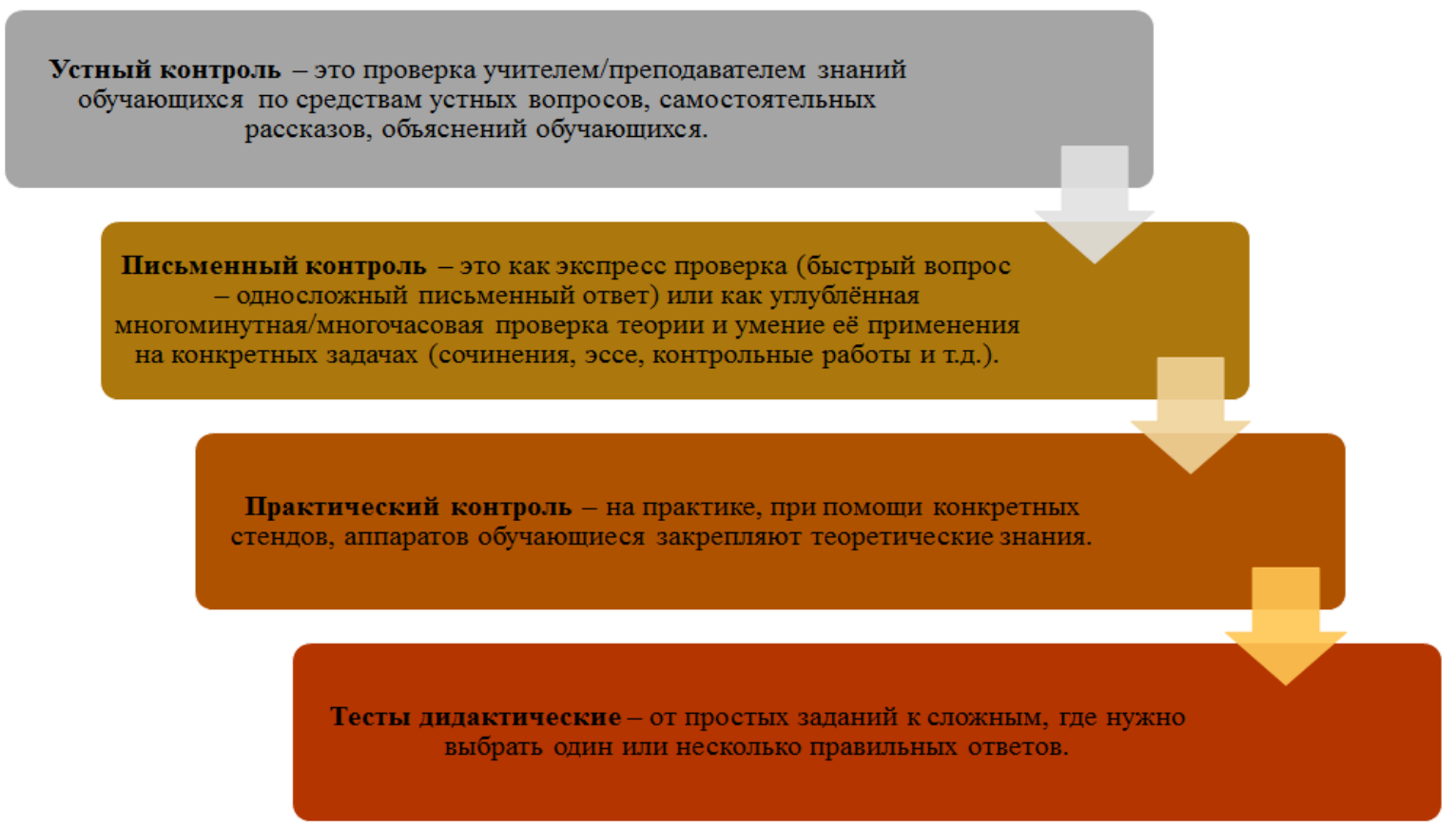

Рис. 3. Методы контроля в педагогике и уточнения

Не будем забывать о наиболее успешных - активных методах обучения, которые позволяют побуждать интерес обучающегося к учебному процессу без психологического давления.

Активные методы обучения (AMO) - это система методов, обеспечивающих активность и разнообразие мыслительной и практической деятельности обучающихся в процессе усвоения учебного материала [6].

AMO могут использоваться на различных этапах учебного процесса: при первичном знакомстве обучающегося с новой темой (проблемная лекция, учебная дискуссия, анализ конкретных ситуаций, кейс-технология, видеоанализ и многое другое); при контроле освоения знаний/закрепление материала (коллективная мыслительная деятельность - деловая игра, ролевая игропрактика, игровое проектирование, арт-метод и многое другое) [6].

Макаренко А.С. считал, что игра обеспечивает высокую эффективность любой деятельности и способствует гармоничному развитию личности, так как «хорошая игра» обязательно содержит в себе усилие (физическое, эмоциональное, интеллектуальное или творческое), доставляет радость (творчества, победы) и налагает ответственность на участников [5]. 
Главное отличие игры от других видов деятельности в том, что её предметом является сама человеческая деятельность, «игрой человека, отмечает Пономарев В.Д., - является такое воссоздание человеческой деятельности, при котором из нее выделяется ее социальная, собственно человеческая суть - ее задачи и нормы отношений между людьми» [5].

Кто сказал, что контроль не может быть творчески-педагогическим? Благодаря активным методам обучения, которые используют прогрессивные педагоги, снижается уровень стресса и напряжённости у обучающихся СПО и ВО. Во время игры формируется благоприятная обстановка в учебном коллективе она способствует самореализации, социализации, здоровой конкуренции и других педагогически-положительные функций.

Конечно, в образовательном учреждении должны быть предпосылки к творческо-педагогическому контролю - это техническое оснащение, Интернет, удобная мебель, освещение, лаборатории с необходимыми узконаправленными предметами и многим другим. Главным деятелем и создателем новых активных форм контроля является преподаватель.

Преподаватель - это сосуд, который должен быть наполнен различными методами, техниками, приёмами обучения, компетенциями. Активная жизненная позиция, толерантное отношение, справедливость и постоянный поиск в совершенствовании подачи информации, стимулирования и контроля учебного маршрута обучающегося - есть залог успешности педагога и обучающегося как будущего специалиста.

\section{Список литературы}

1. Вишневская В.П. Педагогические условия управления учебным процессом педагогического колледжа: Дисс., научн. рук.: Беликов В.А., Семенов В.П.; МГПИ - Магнитогорск, 2019. - С. 23.

2. Контроль как базовая функция педагогического управления - URL: https://pedsovet.su/publ/28-1-0-1062 (дата обращения: 23.12.2021).

3. Понятие контроля в обучении. Задачи и функции контроля - URL: https://www.sites.google.com/site/pedagogikahome/home/tema-7-1-ponatie-kontrolav-obucenii-zadaci-i-funkcii-kontrola_(дата обращения: 23.12.2021).

4. Сластенин В.А., Шиянов Е.И., Исаев И.Ф., Мищенок А.И. Педагогика. Учебное пособие. - М.: Магистр, 2018. - 223 с. 
5. Тономарев В.Д., Педагогика игры. Кемерово: Кузбассвузиздат, 2004. $183 \mathrm{c}$.

6. Фанина Г.С., Вавилова Л.Н. Современные способы активизации обучения: Учеб.пособие для студ. высш. учеб. заведений / Т.С. Панина, Л.Н. Вавилова; Под ред. Т.С. Паниной. - М.: Издательский центр «Академия», 2021. - $176 \mathrm{c}$.

(C) К.А. Черепанова, 2022 